\title{
Construction Project Management: An Experiential Learning Case Study
}

\author{
Michael Er
}

\begin{abstract}
Experiential learning exercises have been advocated as a way of improving learning outcomes for students. This paper reviews the different approaches that educators have attempted in introducing such practical learning exercises into the area of construction management degrees. This research develops a case study that focuses on a subject delivered in the Faculty of Design Architecture and Building at the University of Technology Sydney and specifically in the area of Construction Project Management. The subject takes students from a variety of course disciplines to initially develop a construction management plan for building works. Students are then immersed into the proposed project to participate in the building of that structure. The experience of the subjects is proven to be rewarding in providing an object to which students can apply their construction skills. The success of the course was found to be subject to several variables such as the organisation and planning and the attributes of the individual work supervisors, specifically their industry experience and ability to effectively communicate with students.
\end{abstract}

Index Terms-Construction management, experiential learning.

\section{INTRODUCTION}

An underlying principle of the experiential learning process is that people learn from their experiences. Kolb [1] defines the learning process as the creation of knowledge through the "transformation of experience". The incorporation of an experiential learning module into the construction and project management curriculum is one that is also well advocated. Experiential learning affords the student an opportunity to develop tacit knowledge about the construction industry from construction site based exercises.

Polanyi [2] described tacit knowledge as things we know but cannot express in an explicit manner or that is difficult to transfer in a formal systematic language. Nonaka and Takeuchi [3] noted the idea of socialization with respect to tacit knowledge. These researchers believe that it is the sharing of experiences that creates tacit knowledge. The development of tacit knowledge as an argument for work based experiential learning exercise is further supported by [4] who adapts [5] Zone of Proximal Development to that of adult learning in communities of practice. In a Community of Practice people of varying skill levels work together to achieve the communities shared goal and those with less skill will work along side experts. Bellamy notes that the workers with less skill will learn through observation and directed

Manuscript received November 11, 2016; revised December 22, 2016.

Michael Er is with University of Technology Sydney, Australia (e-mail: Michael.er@uts.edu.au). activity from the experts and themselves become experts.

The affordances associated with experiential learning are particularly appropriate in courses in the field of construction and project management. Several researchers in the area of teaching and learning have advocated the benefit that would be gained with the incorporation of "hands-on" exercises for courses in the construction and project management space. Three methods of delivering experiential learning exercises are suggest by [6] as virtual simulations, site visits and hands-on learning exercises.

Virtual exercises have been developed to simulate the construction process such as an Interactive Construction Management Learning System [7], Virtual Coach [8] and Construction Industry Simulations [9]. Although the virtual exercises introduced were seen as successful [6] notes that these simulations lack the real look and feel of hands on participation in projects and do not facilitate interpersonal skills required in the real world.

Senior [10] notes that the best laboratory for construction students is the construction project itself and that there is no substitute for knowledge derived from a guided experience in the field. [7] also suggest that site visits would complement conventional classroom instruction however are difficult to implement due to the difficulties such as gaining access at the required stage of completion and risks on site. Settineni and Williams [11] identified a significant limitation in field trips being these exercises only represent a snap shot of a particular project at the point in time of the visit. A deeper understanding of the construction industry requires a more holistic approach to teaching.

Billet [12] noted that the learning experience of students in a natural setting and using authentic activities has the potential for greater understanding, particularly because such activities in the workplace allows for the access of knowledge that is socially sourced and situationally constituted. Ahern $e t$ al. [13] agreed and reported that concepts like site working practices, client realities, budget realities, safety realities time pressure, physical limitations of people and materials (buildablity) as well as general "know how" could be best addressed using a hands on exercise.

"Whereas traditional teaching methods may suit some course material, the knowledge necessary to perform well in construction is of the higher-order analytical and decision making skills. Such knowledge can best be acquired through sensory perception (visual input), active processing of information (eg experimentation), and interactions [14]. The teaching methods for construction courses, therefore, should involve sensing, visulaising, and actively participating to address students' learning needs." [6]. 
The calls for experiential learning is further supported by [11] noting that construction students with limited construction experience found difficulties in visualising and understanding the complexities such as building components or processes that are explained in the classroom setting. They found that students graduating from courses involved in the construction industry are often unable come to grips with the typical workings of the construction site. The expectation of employers in the construction industry however is that construction and project management graduates should possess both theoretical and practical knowledge of this complex work environment. [11] as well as other researchers such as [15] believe the best way of delivering this knowledge is through hands-on exercises.

The Bachelor of Construction Project Management within the School of the Built Environment at UTS has successfully incorporated an elective subject that immerses students into a construction project. The case study described in this paper was conducted using qualitative research methods and included the use of a survey that was triangulated using open-ended response questions. This paper next provides and overview of the development and implementation of subjects in the area of construction and project management which incorporate experiential learning.

\section{CONSTRUCTION FOR DEVELOPING COMMUNITIES}

The intention behind the creation of the subject "construction for developing communities" was to deliver a subject that firstly actively engaged students with construction practice and secondly provide a context of both general file and construction project implementation in a disadvantaged community. Students participating in the subject are exposed to the technical, economic and social challenges associated with construction in underprivileged environments.

The majority of students participating in the subject are generally enrolled in the Bachelor of Construction Project Management or associated courses such as property economics. The subject encourages additional participation with students from design courses such as Architecture, Design (Interior Design) and Engineering. The engagement between design and construction management students develops an understanding of the inter-discipline skillsets and affords students the development of future professional networks.

Initially students are provided with a basic plan of the construction project of the identified project and basic information such as the materials and location of the work. Students are then placed into assignment groups to develop a plan to manage a proposed build. The management plans included scoping the works, developing a build program, producing a risk management plan for working on a building site as well as a general risk plan for living and working in a developing community such as Cambodia.

Following the completion of management plans the students travelled and worked together to undertake the construction of the subject build project. The student cohort was divided into groups of six (6) to eight (8), with each group allocated responsibility for the delivery of a building structure. Each group was lead and supervised by a construction industry professional. As part of the preparation for this subject students indicated what experience they had (if any) in terms of "hands on" working on construction sites. The experienced students were distributed through the groups with the idea of creating a community of practice within each group. It should be noted that for the purposes of this paper, the term "community of practice" is defined as "people who engage in the process of collective learning in a shared domain of human endeavour" [16]. Working in such a community of practice group was implemented to afford student the opportunity to develop knowledge in a tacit manner through learning by observing and interacting with others with a greater skill level [17].

The deliverable student works on which assessment is based include the management plans which addressed the construction of the subject project, participation on the actual build and a reflection which considers the difference between what they had planned and reality of the build they experienced in a developing community.

From 2010 till 2014 the location of the subject project (where the hands-on building works are carried out) has been Koh Ramdual Island, a small, physically isolated and resource poor community. The island is located in the middle of a river with limited access. During the rainy season the island sometimes falls below the level of the river.

\section{Methodology}

The research in this paper describes the pilot case study and initial findings of a study on the management of construction projects in Vietnam. The research is qualitative in nature as the investigation considers themes of project management interpreted through the lens of Activity Theory.

Student feedback surveys were conducted online at the conclusion of each teaching semester. The data collection for this research consisted of the student feedback of participating students across five (5) years between 2010 and 2014 while the subject was run in the developing community of Koh Ramdual, Cambodia. Students were surveyed on several questions including the following:

- My learning experience in the subject was interesting and thought provoking; and

- Overall I am satisfied with the quality of the subject; Student responses were collected on a Rensis Likert scale ( 1 - strongly disagree, 2 - disagree, 3 neutral, 4 - agree and 5 - strongly agree) with the possibility of 0 for a non-response or if the respondent considered the question not applicable.

To gauge the effectiveness of individual supervisors leading the build teams, students were questioned about their satisfaction with the staff member and their ability to facilitate learning in the subject.

Each of the above survey questions allowed for further comment using open-ended responses from students to detail their reaction to questions. Two (2) open-ended questions were added to the student survey which allows students to detail a critique of the subject and provide feedback describing what improvements could be made from the 
students perspective. The additional questions were:

- What did you particularly like about the subject; and

- Please suggest any improvements that could be made to this subject?

Open-ended questions were subject to a thematic analysis.

\section{FINDINGS AND DISCUSSION}

The Rensis Likert survey responses are summarised in Table 1 below. Additionally, similar survey responses for other subjects in the same teaching period for both the discipline (subjects in the Bachelor of Construction Project Management) and across the entire faculty (including subjects in architecture and design) are provided.

\begin{tabular}{|c|c|c|c|c|c|}
\hline Questions & 2010 & 2011 & 2012 & 2013 & 2014 \\
\hline $\begin{array}{l}\text { My learning experience in } \\
\text { the subject was interesting and } \\
\text { thought provoking }\end{array}$ & 4.90 & 5.00 & 5.00 & 4.82 & 5.00 \\
\hline $\begin{array}{l}\text { My learning experience in } \\
\text { the subject was interesting and } \\
\text { thought provoking - Course } \\
\text { Average }\end{array}$ & 3.72 & 3.83 & 3.82 & 3.87 & 3.95 \\
\hline $\begin{array}{l}\text { My learning experience in } \\
\text { the subject was interesting and } \\
\text { thought provoking - Faculty } \\
\text { Average }\end{array}$ & 3.79 & 3.90 & 3.89 & 3.91 & 3.98 \\
\hline $\begin{array}{l}\text { Overall I am satisfied with } \\
\text { the quality of the subject }\end{array}$ & 4.86 & 5.00 & 4.94 & 4.82 & 5.00 \\
\hline $\begin{array}{l}\text { Overall I am satisfied with } \\
\text { the quality of the subject - } \\
\text { Course Average }\end{array}$ & 3.66 & 3.82 & 3.80 & 3.81 & 3.92 \\
\hline $\begin{array}{l}\text { Overall I am satisfied with } \\
\text { the quality of the subject - } \\
\text { Faculty Average }\end{array}$ & 3.66 & 3.77 & 3.76 & 3.80 & 3.87 \\
\hline
\end{tabular}

Overall, the Construction for Developing Communities subject performed significantly better than the averages of other subjects offered across both the course and faculty subjects in all questions associated with the quality of teaching and learning. For example in analysing the overall satisfaction with the quality of the subject by students the mean for the Developing Communities subject across the 5 year period was 4.92 with a standard deviation (SD) of 0.07 whereas for the same time period for the faculty the mean was 3.77 with a SD of 0.07 . Similar to the faculty outcomes, the Bachelor of Construction Project Management course had a mean result of 3.80 and SD of 0.83 . Additionally, when questioned if the subject was interesting and thought provoking the case study subject again returned a superior result with a mean of 4.94 as opposed to the course (3.84) and wider faculty (3.89). The survey results appear to be consistent with previous research undertaken in the area of experiential learning and construction management (see introduction). That is it indicates this experiential learning exercise was effective in providing a platform for understanding construction related work.

The satisfaction with the quality of the subject indicated in the survey results, was supported with a consistent theme of satisfaction with the quality of the subject in the open-ended responses from the students. Typical comments in the area of quality included suggestions that the subject consisted of "extremely high quality teaching resources and an excellent experience" and "It was an amazing subject, well run and would recommend it to anyone".

A thematic analysis exploring the relative success associated with this subject was undertaken using the open-ended responses provided as part of survey results. It was clear that students in general enjoyed the subject and was a unique experience in their studies. For example, some of the open-ended responses included "the whole experience was fantastic, I want to do it again!"; "great experience, an opportunity I would recommend to anyone and everyone something I will never forget and I hope the people that we built the hut for have been helped in some way. I would like to return there one day if possible for another build"; and "It gives an excellent experience unparalleled by any other subject I have completed".

Much research in teaching and learning for construction courses support integration of hands-on, "real-life" projects into the curriculum. Researchers such as [12] proposed that exercises that are situated in a natural setting using authentic exercises provides for a higher-level understanding as it is "socially sourced and situationally constituted". Supporting the need for realistic exercises in the curriculum, [7] believe that the immersion into a real-life project assists students construction courses overcome issues such as knowledge fragmentation, where students generally undertake separate, specific topic areas associated with construction. They suggest that students do not retain their knowledge of previous courses and to address such inadequacy students must be holistically challenged in their studies. Ahern et al. [13] report on the development of an experiential learning project (the "Constructionarium") aimed at fulfilling this need. The Constructionarium facilitated a hands-on construction project for engineering students undertaken in a control environment on the grounds of the National Construction College (UK). The shortfall identified in the delivery of this module was that they did not have a real client and meant that consequences, such as meeting the client's quality requirements, were not a reality. Several other themes were uncovered which are consistent with findings of previous researchers.

In our case study subject, students engaged in hands-on construction projects that incorporated interaction with clients and local tradesmen. Students participated in the broader scenario of planning, managing as well as the physical construction of a building project. They were required to work closely with the nominated charities and interact with the eventual users of the buildings they worked on (the end-user client). Students acknowledged the holistic approach to learning. For example, one student noted that the subject “... was a more life experience which you do not get with any other subjects. It was also helpful as it gives a hands on approach to construction as for many of us in the construction industry we are more concerned with the actual management of construction" while another student commented "The fact that this subject pushed me out of my comfort zone made it extremely interesting. Completing work for charity meant that the subject was worthwhile, particularly more so than classes undertaken at campus... Construction for Developing Communities is definitely a subject that I 
would recommend to all students at UTS..."

Another attribute of the subject was to develop communities of practice in which the students completed the planning and hands-on construction works in teams. Several researchers in the area of teaching and learning advocate the potential offered by working in communities of practice and collaboration (see Introduction, [4]) with workers with less skill learning from experts. Further, the construction industry is one that is collaborative in nature and individual workers need to learn how to collaborate [18]. The analysis of feedback found themes indicating that students both benefited (learnt) from working in the community of practice as well as enjoying the opportunity to work in teams with students noting that "very practical and helped develop my skills of working with people with different fields" while another commented that the subject "was a great way to meet and bond with other students".

Although some students identified the construct of a community of practice and associated 'zone of proximal learning' based on fellow students an even clearer theme identified by the students was the dependence of learning on the abilities of the university staff member supervising their construction work. The two main attributes which lead students to learn and work well with the staff supervisor were:

1) Their practical (hands-on) experience and construction skills

2) The ability to effectively communicate with their student group.

Most members of the supervising staff have significant hands-on experience working in the construction industry. Some possessed trade qualifications such as carpentry or bricklaying, while others had spent significant time supervising and labouring (hands-on work) of construction projects. There were two incidences where a supervisor did not possess hands-on experience of building work. These staff members were experienced in off-site construction roles including design and quantity surveying. In general students scored their satisfaction with teaching for both these members of staff significantly lower than that of the other staff in the survey. For example, in 2010, while the other two staff members scored survey results of 4.90 and 4.55 for their satisfaction with teaching, the supervisor with limited hands on experienced scored 3.95. The result for the inexperienced staff member was relatively consistent with the faculty average in the same period (3.92) however this is significantly less that the experienced supervisors result. Over the course of the build students were able to identify the hands on construction experience levels of the individual supervisors. The student's perception of the supervisor's construction experience appears to be directly related to their satisfaction with the quality of teaching. Students acknowledged the relationship between experience and quality of teaching with critical open ended responses about the inexperienced staff member such as, they "did not have the knowledge of construction" to satisfactorily teach the subject.

The ability to communicate with students was also identified as an important factor in the learning experience in this case study. This was highlighted when one of the staff members with a trade background scored relatively poorly in the survey question related to satisfaction with their teaching.
In this scenario two supervisors had comparable construction site experience however one of the staff members scored a 5.0 for student satisfaction with the quality of their teaching whereas another supervisor scored significantly lower at 4.0. The open ended feedback noted that the supervisor that scored 5.0 was an "excellent teacher and engages with students" whereas the feedback for the other supervisor indicated difficulties inn communicating with students and was thought of as distant and "a bit angry". The combined lower survey feedback with comments noting the ability to engage with students provides an indication that the ability to communicate effectively by the supervisor is potentially a contributor to the successful learning by students.

Other emergent themes were identified as contributors to the success of the learning in the case study subject were made salient by the student feedback. Firstly, students found the subject to be the unique, different from other subjects that they had undertaken in their previous studies. This was partially due to the hands-on nature of this subject but also the integration and work with the not-for-profit organisations. Some of the unique features noted in student feedback included the opportunity to work with tradesmen and workers that do not speak the same language yet completing the building project through common construction knowledge and developing an understanding of construction in a developing country. The work with charities was a clear theme expressed by students with one commenting that they "were able to help do something that would practically help people in another country who need our help whilst not only learning about construction practices, their differences and also about the culture itself" And another noting "The chance to help disadvantaged people and giving back. Very rewarding way to finish my degree".

The work with not-for-profits is mutually beneficial in that students gain the experience of working on a construction project and the charity is able to fulfil their assistance to the local community. Sawheny and Mund [7] identify the incorporation of site visits and training as ideal for construction management students but noted that practical components are difficult to implement into teaching as they involve such issues ensuring availability of work and in some cases the construction site personnel may not welcome groups of students. The charities that have collaborated in the case study subject appear to have an endless need for construction works and welcome students to the work site and into the community they are working in.

\section{CONCLUSION}

Students involved in the case study subject participated in an experiential learning process in which they effectively planned, managed and physically constructed a variety of building works. Student survey feedback across a five (5) year period consistently acknowledged the quality of the subject with superior results when compared against other subject taught across the construction course and the wider faculty. The holistic and realistic nature of the case study subject, incorporating the planning, management and physical construction of building works, was found to be an effective learning exercise. The results associated with the high quality 
of the subject are consistent with previous research in the area of experiential and project based learning for construction students. The case study subject is an elective open to students from construction related disciplines. The interaction with students from related disciplines appears to be another positive outcome identified by students. The resultant teamwork and collaboration between students has been identified in previous research as key skills required for the construction industry.

The analysis of open-ended student responses identified several themes that significantly contributed to the success of the teaching and learning of the subject. Working with a charity afforded students a feeling of satisfaction and produced building works that supported the developing community while the operation of the subject benefited from an ongoing supply of construction projects. The attributes of the staff played an important role in student satisfaction with the supervision and quality of the subject. Two key attributes of supervising staff that were established are their hands-on building experience and their ability to communicate.

\section{REFERENCES}

[1] D. Kolb, Experiential Learning: Experience as the Source of learning and development, Prentice-Hall, New Jersey, p. 41, 1984.

[2] M. Polanyi, The Tacit Dimension, Doubleday, Gloucester, UK, 1966.

[3] I. Nonaka and H. Takeuchi, The Knowledge Creating Company, Oxford Press, New York, 1995.

[4] R. Bellamy, Designing Educational Technology, Context and Consciousness, MIT Press, Cambridge, Massachusetts, pp. 123-146, 2001.

[5] L. S. Vygotsky, Mind in Society: The Development of Higher Psychological Processes, Harvard University Press, 1980.

[6] T. Hegazy, M. Bdel-Monem, D. Saad, and R. Rashedi, Journal of Construction Engineering and Management, September, pp. 1135-1143, 2013.

[7] A. Sawhney and A. Mund, "Simulation based construction management learning system," in Proc. the 1998 Winter Simulation Conference, 1999.

[8] E. M. Rojas and A. Mukherjee, "General-purpose situational simulation environment for construction education," Journal of
Construction Engineering and Management, vol. 131, no. 3, pp. 319-329, 2005.

[9] T. Korman and H. Johnston, "Enhancing construction engineering and management education using a construction industry simulation (COINS)," Computing in Civil Engineering, 2011.

[10] B. Senior, "Infusing practical components into construction education," Journal of Construction Education, Summer 1998, vol 3, no.2, pp. 92-101,1998.

[11] A. Sattineni and S. Williams, "Paving new roads to knowledge: An experiment to enhance construction teaching," Journal of College Teaching and Learning, vol. 5, no. 4, pp. 39-48, 2008.

[12] S. Billet, Learning through Work, in Workplace Learning in Context, 2004.

[13] A. Ahearn, S. Popo-Ola, A. Ciribini, and G. Girmscheid, "A cultural divide? Different modes of teaching construction management," in Proc. First EUCEET Association Conference: New trends and Challenges in Civil Engineering Education, 2011.

[14] R. M. Felder and L.K. Silverman, "Learning and teaching styles in engineering education," Engineering education, vol. 78, no. 7, pp. 674-681,1998.

[15] A. Mills, D. Wingrove, and P. McLaughlin, "Exploring the development and assessment of work-readiness using reflective practice in construction education," in Proc. $26^{\text {th }}$ Annual ARCOM Conference, Leeds, UK, 2010.

[16] E. Wenger. (2004). Communities of Practice: A brief introduction, National Science Foundation (US). [Online]. Available: http://hdl.handle.net

[17] J. Kamara, G. Augenbroe, C. Anumba, and P. Carillo, "Knowledge management in the architecture, engineering and construction industry," Construction Innovation, vol. 2, pp. 53-67, 2002.

[18] R. Creasey, "Improving students' employability," Engineering Education, vol. 8, no. 1, pp.16-30, 2013.

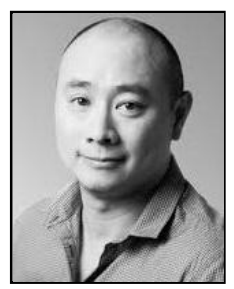

Michael Er was born in Australia, in 1969. He was graduated from a bachelor of building from the University of NSW, a graduate diploma in IT, a masters in information technology and a $\mathrm{PhD}$ in computer science from the University of Technology Sydney.

$\mathrm{He}$ is currently a senior lecturer in the Faculty of Design Architecture and Building at the University of Technology Sydney.

He has over 20 years professional experience in Construction Project Manager and Management Consulting. His published research encapsulates information systems, innovation, project management, education and the application of Activity Theory. 